\title{
Alcohol dependence treatment in the EU: A literature search and expert consultation about the availability and use of guidelines in all EU countries plus Iceland, Norway, and Switzerland
}

\author{
Jürgen Rehm ${ }^{1,2,3,4,5}$, Maximilien Xavier Rehm ${ }^{6}$, Hannu Alho ${ }^{7}$, Allaman Allamani ${ }^{8}$, Henri-Jean Aubin ${ }^{9}$, \\ Gerhard Bühringer $^{5,10}$, Jean-Bernard Daeppen ${ }^{11}$, Ulrich Frick ${ }^{12}$, Antoni Gual ${ }^{13}$, and Nick Heather ${ }^{14}$ \\ ${ }^{1}$ Social and Epidemiological Research (SER) Department, Centre for Addiction and Mental Health, Toronto, Canada \\ ${ }^{2}$ Dalla Lana School of Public Health, University of Toronto, Toronto, Canada \\ ${ }^{3}$ Department of Psychiatry, Faculty of Medicine, University of Toronto, Toronto, Canada \\ ${ }^{4}$ Institute of Medical Science, University of Toronto, Toronto, Canada \\ ${ }^{5}$ Technische Universitaet Dresden, Klinische Psychologie \& Psychotherapie, Dresden, Germany \\ ${ }^{6}$ Ryerson University, Faculty of Arts and Sciences/Politics and Governance, Toronto, Canada \\ ${ }^{7}$ Unit of Substance Abuse Medicine, Faculty of Medicine and Helsinki University Hospital, University of Helsinki, Helsinki, Finland \\ ${ }^{8}$ Agenzia Regionale di Sanità, Firenze, Italy \\ ${ }^{9}$ Hôpital Paul Brousse, Hôpitaux Universitaires Paris-Sud, AP-HP, INSERM U 669, University Paris-Sud, Paris, France \\ ${ }^{10}$ IFT Institut für Therapieforschung, Munich, Germany \\ ${ }^{11}$ Alcohol Treatment Center, Lausanne University Medical School, Lausanne, Switzerland \\ ${ }^{12}$ Psychiatric University Hospital, Regensburg, Germany \\ ${ }^{13}$ Unitat d'Alcohologia, Hospital Clinic, Barcelona, Spain \\ ${ }^{14}$ Faculty of Health \& Life Sciences, Northumbria University, Newcastle Upon Tyne, United Kingdom
}

\section{Abstract}

Aim: To describe guidelines and common practices for alcohol dependence treatment in Europe.

Design: Systematic and qualitative review; for each country, guidelines were identified via systematic literature research, followed by interviews with treatment experts.

Setting: European Union (EU) countries plus Iceland, Norway, and Switzerland.

Participants: Experts in alcohol dependence treatments and treatment systems.

Measure: Semi-structured questionnaire for interviews.

Findings: While fewer than half of EU countries have formal national guidelines for alcohol dependence treatment, a majority of these countries have guidelines by professional organizations such as psychiatric or neuropsychopharmacologic societies, and several are currently developing such guidelines. Abstinence is the usual treatment goal, but the majority of countries accept reduction of drinking as an intermediate or secondary goal, in practice even more than in the guidelines. Psychotherapy, mainly cognitive-behavioral approaches, motivational interviewing, and family therapy, is the most common treatment for relapse prevention, in part accompanied by pharmacotherapy (disulfiram, acamprosate and naltrexone being used most often).

Conclusions: There are differences in treatment for alcohol dependence in Europe. The introduction of reduction of drinking as one treatment goal may attract more patients.

Alcohol Use Disorders (AUD) in general, and Alcohol Dependence (AD) in particular, are important contributors to burden of disease (Rehm et al., 2009). Based on the most recent update of the Global Burden of Disease (GBD) study for the year 2004 (World Health Organization [WHO], 2008), AUD were responsible for $5.3 \%$ of all burden of disease and injury in the European Union (EU) in men, and $1.3 \%$ in women (Wittchen et al., 2011), with enormous costs associated (Gustavsson et al., 2011). The AUD-related burden of disease and injury in the eastern part of the EU, in mid-income countries, is the highest within the EU (Rehm et al., 2007; Rehm, Zatonski, Taylor, \& Anderson, 2011).

Correspondence: Jürgen Rehm, Centre for Addictions and Mental Health (CAMH), 33 Russell Street, Toronto, Ontario, Canada, M5S 2S1; Telephone: 1-416-5358501 ext. 6173; Fax: 1-416-595-6033

Financial Support: Supported by an unrestricted grant of H. Lundbeck A./S. Support to CAMH for salary of scientists and infrastructure is provided by the Ontario Ministry of Health and Long Term Care.

Keywords: alcohol dependence, treatment, abstinence, reduced drinking, pharmacotherapy 
Given this situation, evidence-based means to reduce burden are important. One such means is alcohol dependence treatment (ADT). However, $\mathrm{AD}$, like most other mental disorders, is severely undertreated; that is, most people with $\mathrm{AD}$ do not seek or receive treatment (Alonso et al., 2004) (for mental health in general, see Dezetter et al., 2011). In the European Study of the Epidemiology of Mental Disorders (ESEMeD), with general population surveys in Belgium, France, Germany, Italy, the Netherlands, and Spain, only 8.3\% (95\% CI: $3.8 \%-12.8 \%)$ of those with AUD in the past 12 months consulted any mental health service in that period; this proportion of health service utilization is even smaller than the proportion for other mental disorders (any mental disorder: 25.7\%, 95\% CI: 23.35-28.15; all prevalence from Alonso et al., 2004). The majority of services were from mental health professionals, mostly psychologists or addiction counselors, or from a combination of General Practitioners (GP) and mental health specialists (Alonso et al., 2004). The majority of treatments (2/3) involved psychological interventions, either alone or in combination with drug treatment. Pharmacological treatment was used in about $50 \%$ of cases, with $60 \%$ of all pharmacological treatment occurring in combination with psychological interventions (Alonso et al., 2004). A more recent review found similar treatment utilization rates, with an overall proportion of less than $10 \%$ of all people with AD being in treatment in the same year (Rehm, Shield, Rehm, Gmel, \& Frick, 2012, 2013).

In the ESEMeD study, no further questions were asked concerning details of ADT, including goals. As ADT traditionally can take different forms with different goals (Hamburg, 1975; Klingemann, Takala, \& Hunt, 1992; Mäkelä \& Säilä, 1987), knowledge about goals may be important in shaping future ADT, and may contribute to future increases in delivering $\mathrm{ADT}$ to all who need it (Drummond et al., 2011).

It is the aim of this paper to provide a detailed description of ADT in all countries of the EU plus Iceland, Norway, and Switzerland by giving the specifics of current treatment practices, including specification of treatment goals, differential indications, and the psycho- and pharmacotherapies used. This description is primarily based on treatment guidelines, which exist in about half of the countries. In addition to analyzing these guidelines, we asked experts about their clinical practice - that is, whether the guidelines were followed. For countries without guidelines, we have tried to describe clinical practice based on the published literature and an expert opinion survey only.

\section{Method}

We first identified treatment guidelines via searches of the published and unpublished literature and a key informant survey, using a procedure similar to the MOOSE guidelines (Stroup et al., 2000). Guidelines were defined as systematically developed formal recommendations based on scientific evidence, expert opinion, and service user preferences to assist professionals and service users in making decisions about appropriate alcohol dependence treatment interventions for specific circumstances (Field \& Lohr, 1992). Our focus was restricted to the main postacute treatment phase; thus, we do not list guidelines if they only cover treatment of withdrawal or detoxification, or if they only cover the best handling of delirium tremens (Leentjens \& Diefenbacher, 2006).

The systematic search was completed to identify original research articles published between April 1985 and March 15th, 2011. The database searched was Medline, with Google as a second database. We considered both drafts and published guidelines, in English as well as the national language(s) of the country in question (Google Translate was used extensively to find and translate relevant publications).

The search strategy consisted of the following search terminology: (Alcohol Dependence OR Alcoholism) AND (Guideline OR Recommendation) AND treatment AND (Europe OR Austria OR Belgium OR Bulgaria OR Cyprus OR Czech Republic OR Denmark OR Estonia OR Finland OR France OR Germany OR Greece OR Hungary OR Iceland OR Italy OR Latvia OR Lithuania OR Luxembourg OR Malta OR The Netherlands OR Norway OR Poland OR Romania OR Slovakia OR Slovenia OR Spain OR Sweden OR Switzerland OR United Kingdom OR England OR Scotland OR Wales OR Northern Ireland).

In addition, we identified experts in each country to comment on the results of our search, which we summarized in a small Excel table. Experts with knowledge of the treatment system were identified via personal references and on the basis of their published literature on this topic. Solicitations for response were sent out between July 1, 2011, and September 15, 2011. In total, 37 experts from 26 countries responded and, based on these responses, we either followed up with additional experts from these countries or finalized the assessment.

\section{Results}

Figure 1 gives an overview of the systematic search (Stroup et al., 2000).

Twenty-five national or professional guidelines were identified from 16 countries (see Table 1 for an overview of all guidelines identified).

A number of the guidelines were national, that is, formally approved by the respective ministries or other regulatory agencies. Some of these were issued by professional organizations. Only exceptionally were guidelines written by researchers without institutional or organizational backing (Kienast \& Heinz, 2005). Guidelines were usually based on a review of the available evidence, sometimes 
Figure 1

Results of the systematic search

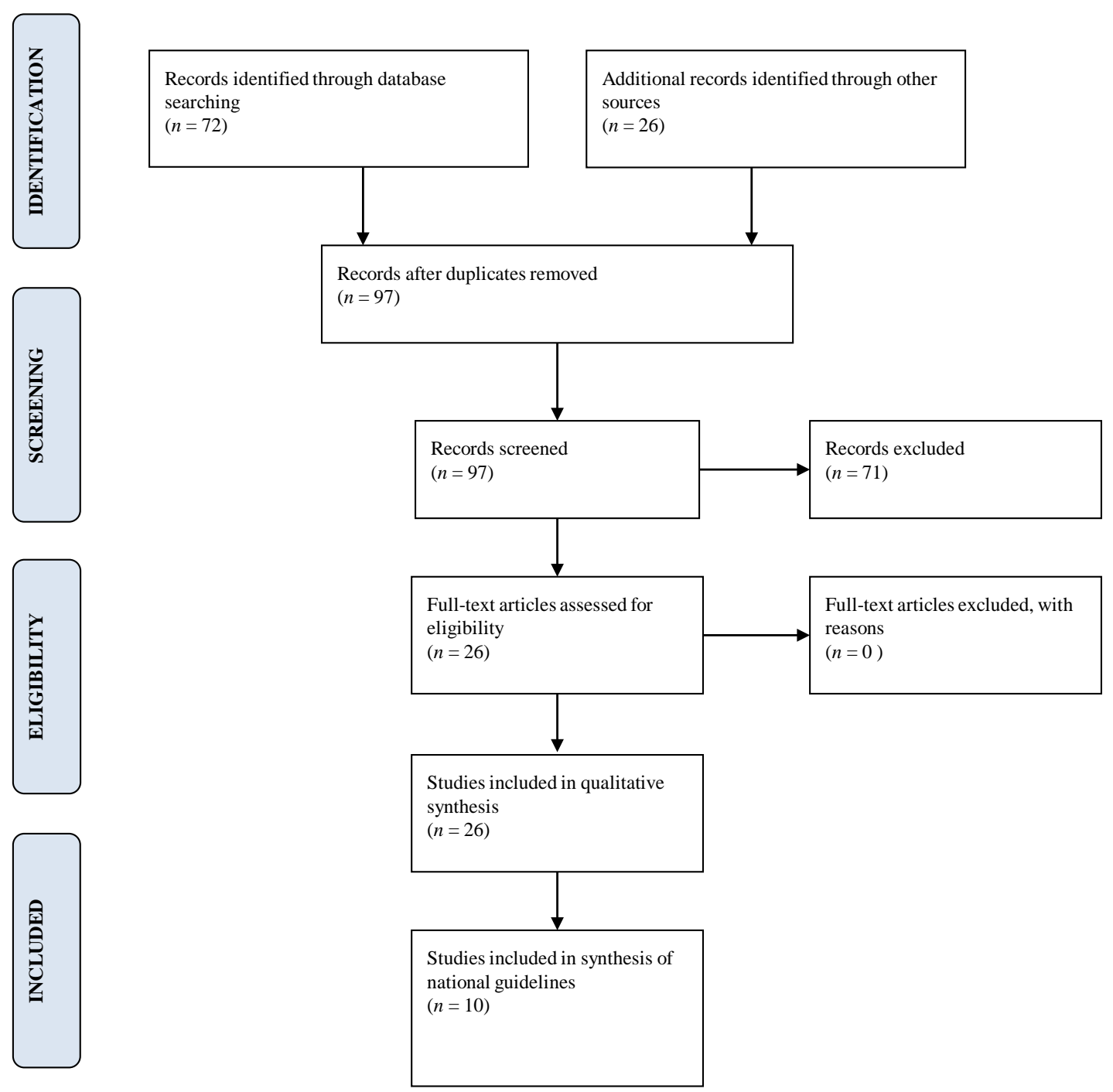

included in the guidelines (National Institute for Health and Clinical Excellence [NICE], 2011). The English-language guidelines were sometimes based on a separate review (Raistrick, Heather, \& Godfrey, 2006).

As for the aims of ADT, some guidelines refer to wider goals, such as reintegration into the remunerated working environment and overall physical and psychosocial rehabilitation (Rentenversicherung Bund, 2009). Most guidelines mention abstinence, either as the ultimate goal (see also Appendix Table 1) or as one of the goals. However, in several national guidelines, reduced or controlled drinking is also accepted as an ultimate, intermediate, or other treatment goal. An overview of the different views on reduced consumption/controlled drinking in the various guidelines and in clinical practice can be found in Table 2 .
Several guidelines make some kind of differential indication: abstinence is the goal for severe dependence, and/or if somatic complications are present. As well, abstinence is, of course, the goal if the patient wishes to become abstinent. Reduced drinking is often the goal for less severe dependence, if abstinence treatment has failed (and some guidelines explicitly speak about harm reduction in this context), or if this is the only goal the patient is willing to accept.

Reduction of drinking is also accepted as a legitimate outcome in countries without formal guidelines, and even, in practice, in countries with national or organizational guidelines which have an abstinence goal. Thus, if a de facto reduction of consumption approach exists in the practice of a country like Italy, it is seen as the consequence of the fact that some patients do not stop drinking. These 
Table 1

National and professional guidelines for alcohol dependence treatment in Europe 2011

\begin{tabular}{|c|c|}
\hline Country & National guideline available (reference) \\
\hline Austria & No \\
\hline Belgium & No, but under development \\
\hline Bulgaria & No, but under development \\
\hline Cyprus & Yes (Cyprus Anti-Drugs Council, 2010) \\
\hline Czech Republic & No \\
\hline Denmark & $\begin{array}{l}\text { No, but there is a professional assessment of options and recommendations from the National Board of Health, Danish } \\
\text { Centre for Evaluation and Health Technology Assessment, which is close to a national set of guidelines }\end{array}$ \\
\hline Estonia & $\begin{array}{l}\text { No, although there are guidelines for drug abuse treatment which do not specifically include ADT } \\
\text { (http://www.emcdda.europa.eu/attachements.cfm/att_101778_EN_EE01_alcohol\%20+\%20drugs.pdf) } \\
\text { Archived: http://www.webcitation.org/60WTQhJ3R }\end{array}$ \\
\hline Finland & No \\
\hline France & $\begin{array}{l}\text { Yes (Société Française d'alcoologie, 2001) http://www.sfalcoologie.asso.fr/download/SFA_conduites-alcool.pdf } \\
\text { Archived: http://www.webcitation.org/60duwn24R http://www.webcitation.org/60duwn24R } \\
\text { also http://www.has-sante.fr/portail/upload/docs/application/pdf/alc2.pdf }\end{array}$ \\
\hline Germany & $\begin{array}{l}\text { Yes: federal guidelines for all psychotherapy, which explicitly deal with ADT (2011): } \\
\text { Richtlinien des Gemeinsamen Bundesausschusses über die Durchführung der Psychotherapie (Psychotherapie-Richtlinie). } \\
\text { In der Fassung vom 19. Februar } 2009 \text { veröffentlicht im Bundesanzeiger 2009; Nr. 58: S. 1399; zuletzt geändert am } \\
\text { 14.04.2011 veröffentlicht im Bundesanzeiger Nr. } 100 \text { vom 7. Juli } 2011 \text { in Kraft getreten am 8. Juli } 2011 \\
\text { (http://www.kvwl.de/arzt/recht/kbv/richtlinien/richtl_psycho.pdf ) }\end{array}$ \\
\hline Greece & No \\
\hline Hungary & $\begin{array}{l}\text { Yes (http://www.eum.hu/egeszsegpolitika/minosegfejlesztes/pszichiatria ) } \\
\text { Archived: http://www.webcitation.org/60IYVTHVD }\end{array}$ \\
\hline Iceland & $\begin{array}{l}\text { Yes (http://landlaeknir.is/pages/1210 ) Archived: http://www.webcitation.org/60V8ixAJp } \\
\text { (Össurarson, Gudmundsson, Olafsdóttir, Jónsson, \& Halldórsson, 2007) }\end{array}$ \\
\hline Ireland & No \\
\hline Italy & No \\
\hline Latvia & No \\
\hline Lithuania & No \\
\hline Luxembourg & No, but guidelines are under development \\
\hline Malta & No \\
\hline The Netherlands & Yes (Multidisciplinaire Richtlijnontwikkeling G. Z. Z., 2009) \\
\hline Norway & No \\
\hline Poland & Yes (http://fas.nazwa.pl/parpa_en/images/stories/ACT.pdf ). Archived: http://www.webcitation.org/60NBYx1sc \\
\hline Portugal & No \\
\hline Romania & No \\
\hline Slovakia & No \\
\hline Slovenia & $\begin{array}{l}\text { Yes: Osnove zdravljenja odvisnosti od alkohola. Uèbenik in smernice za delo from 2004. (Fundamentals for Treatment of } \\
\text { Alcohol Dependence). Guidelines adopted by the College of Psychiatry at the Ministry of Health. }\end{array}$ \\
\hline Spain & No \\
\hline Sweden & Yes (http://www.socialstyrelsen.se/publikationer2007/2007-102-1). Archived: http://www.webcitation.org/60Iqaoo8c \\
\hline Switzerland & No \\
\hline United Kingdom & $\begin{array}{l}\text { Yes: England \& Scotland. England: for underlying evidence (Raistrick et al., 2006) } \\
\text { http://www.lho.org.uk/Download/Public/10776/1/Models\%20of\%20care\%20for\%20alcohol\%20misusers.pdf } \\
\text { (Archived: http://www.webcitation.org/60ctSJIHl) } \\
\text { Scotland (Intercollegiate Guidelines Network, 2003) http://www.sign.ac.uk/pdf/sign74.pdf } \\
\text { Archived: http://www.webcitation.org/archive.php } \\
\text { Guidelines provided by the National Institute for Health and Clinical Excellence, an arm's-length organization, are for the } \\
\text { whole UK, but National Health Service (NHS) organizations are audited by the Department of Health on their compliance } \\
\text { with the guidelines: }\end{array}$ \\
\hline
\end{tabular}




\begin{tabular}{ll}
\hline Country & National guideline available (reference) \\
\hline NICE UK guidelines (NICE, 2011): \\
http://www.nccmh.org.uk/downloads/Alcohol_dependence/CG115_Full_Guideline.pdf \\
Archived: http://www.webcitation.org/60V1FV0Lm \\
\hline
\end{tabular}

\section{Other professional guidelines in Europe}

\begin{tabular}{|c|c|}
\hline Country & Other professional guidelines available (reference) \\
\hline Austria & $\begin{array}{l}\text { Guidelines for the elderly from the Austrian Society for Geriatrics and Gerontology } \\
\text { http://www.geriatrie-online.at/dynasite.cfm?dssid=4285\&dsmid=64530\&dspaid=493972 } \\
\text { Archived: http://www.webcitation.org/609QJidS9 }\end{array}$ \\
\hline Czech Republic & $\begin{array}{l}\text { Yes: there are two professional sets of guidelines: } \\
\text { From the Czech Psychiatric Society: (Raboch et al., 2010); and from the Czech Society for Neuropsychopharmacology: } \\
\text { (Seifertová et al., 2008). }\end{array}$ \\
\hline Denmark & $\begin{array}{l}\text { Overview of evidence base on ADT by: National Board of Health, Danish Centre for Evaluation and Health Technology } \\
\text { Assessment } \\
\text { (http://www.sst.dk/publ/Publ2006/CEMTV/Alkoholbeh/MTValkoholbehandling.pdf ) } \\
\text { Archived: http://www.webcitation.org/60V14GSeG }\end{array}$ \\
\hline Finland & $\begin{array}{l}\text { Yes (http://www.kaypahoito.fi/web/kh/suositukset/naytaartikkeli/.../ccs00005 ) } \\
\text { Archived: http://www.webcitation.org/60Gz8g8rX }\end{array}$ \\
\hline Germany & $\begin{array}{l}\text { Rehabilitation guidelines from the German statutory pension insurance scheme (Rentenversicherung Bund, 2009) } \\
\text { Guidelines provided by the medical association, Arbeitsgemeinschaft der } \\
\text { Wissenschaftlichen MedizinischenFachgesellschaften e.V. (AWMF) (Geyer et al., 2006) }\end{array}$ \\
\hline Latvia & Professional guidelines exist (The State Addiction Agency Working Group, 2005) \\
\hline Spain & $\begin{array}{l}\text { Guidelines provided by the professional association Socidrogalcohol (Guardia Serecigni et al., 2008) } \\
\text { (http://www.socidrogalcohol.org/index.php?option=com_docman\&task=doc_download\&gid=88\&Itemid=19 ) } \\
\text { Archived: http://www.webcitation.org/60cFZDjIf }\end{array}$ \\
\hline United Kingdom & $\begin{array}{l}\text { Guidelines provided by the British Association for Psychopharmacology, mainly limited to the pharmacological } \\
\text { management of AD (Lingford-Hughes et al., 2004). After the review, a new iteration of these guidelines appeared, where } \\
\text { reduction of drinking was an acceptable goal except in the presence of some co-morbidities such as liver cirrhosis } \\
\text { (Lingford Hughes et al., 2012) }\end{array}$ \\
\hline Primary Health & Guidelines of this project were applied in: Belgium, Bulgaria, Czech Republic, England, Denmark, Finland, France, \\
\hline $\begin{array}{l}\text { Care European } \\
\text { Project on }\end{array}$ & $\begin{array}{l}\text { Germany, Greece, Hungary, Ireland, Italy, Lithuania, Latvia, Netherlands, Poland, Portugal, Slovenia, Slovak Republic, } \\
\text { Spain. and Sweden }\end{array}$ \\
\hline Alcohol & PHEPA guidelines (English): http://www.gencat.cat/salut/phepa/units/phepa/pdf/cg_1.pdf \\
\hline (PHEPA) & Archived: http://www.webcitation.org/60cFehg0q \\
\hline
\end{tabular}

patients are nevertheless accepted when they attend the professional program; this may create a challenging and creative treatment condition, where an unstable balance is established between the professionals' abstinence goal and the goal of patients to be medically and socially supported. Italy's Hudolin clubs (a self-help organization in aftercare, created in Croatia by the psychiatrist V. Hudolin as part of a treatment program for alcohol dependence) (Sikic, Walker, \& Peterson, 1972), which have an abstinence goal, tolerate people with alcohol dependence who are not able to completely abstain from drinking, but who contradictorily still come to the group and hear the message that they should not drink. The same thing appears to happen even in Alcoholics Anonymous (AA) meetings, where there are members who attend for long periods of time despite being unable to stop drinking.

In France, the abstinence goal is comparatively strongly anchored in the guidelines, but a survey found that nonetheless, $50 \%$ of therapists tolerate a goal of controlled drinking in their daily practice, under certain circumstances (Luquiens, Reynaud, \& Aubin, 2011).

In most countries, ADT-especially for more severe cases-usually comprises a combination of psychotherapy and pharmacotherapy, but psychotherapy alone is used for many therapeutic interventions. Psychotherapy may include close family and significant others. It may take different forms, but cognitive behavioral therapy, motivational interviewing, and social skills training are the most prevalent interventions (Martin \& Rehm, 2011; Miller, Wilbourne, \& Hettema, 2003, for overviews of psychosocial interventions and their effectiveness). In most countries, alcohol support groups are also available, the most common being AA(Mäkelä et al., 1996).

In pharmacotherapy, in addition to benzodiazepines, which are used mainly for detoxification, the three most prevalent drugs used in the EU in the post-acute actual treatment phase are acamprosate, naltrexone, and disulfiram. Rarely 
Table 2

Role of reduced consumption in national guidelines and in practice in $E U$ countries

\begin{tabular}{|c|c|c|c|c|}
\hline \multicolumn{5}{|c|}{ National Guidelines: Role of reduced consumption/controlled drinking..... } \\
\hline $\begin{array}{l}\text { as equal goal for ADT } \\
\text { (alcohol dependence } \\
\text { treatment) }\end{array}$ & $\begin{array}{l}\text { as equal goal for less } \\
\text { severe } \mathrm{AD} \text { (alcohol } \\
\text { dependence) }\end{array}$ & $\begin{array}{l}\text { as alternative when } \\
\text { abstinence fails }\end{array}$ & $\begin{array}{l}\text { as intermediate goal, } \\
\text { with abstinence as final } \\
\text { goal }\end{array}$ & $\begin{array}{l}\text { as option if the patient } \\
\text { requests it }\end{array}$ \\
\hline & & & D (temporary) & \\
\hline & GB (English) & & GB (English) & \\
\hline & GB (Scottish) & & GB (Scottish) & \\
\hline & & $\mathrm{H}$ & $\mathrm{H}$ & \\
\hline NL & NL & & NL & NL \\
\hline S & & & & \\
\hline
\end{tabular}

Cyprus, France, Iceland, Poland, and Slovenia did not mention reduced consumption in their guidelines at all.

\begin{tabular}{|c|c|c|c|c|}
\hline \multicolumn{5}{|c|}{ Practices: Role of reduced consumption...... } \\
\hline $\begin{array}{l}\text { as equal goal for ADT } \\
\text { (alcohol dependence } \\
\text { treatment) }\end{array}$ & $\begin{array}{l}\text { as equal goal for less } \\
\text { severe AD (alcohol } \\
\text { dependence) }\end{array}$ & $\begin{array}{l}\text { as alternative when } \\
\text { abstinence fails }\end{array}$ & $\begin{array}{l}\text { as intermediate goal, } \\
\text { with abstinence as final } \\
\text { goal }\end{array}$ & $\begin{array}{l}\text { as option if the patient } \\
\text { requests it }\end{array}$ \\
\hline \multirow[t]{3}{*}{ A (elderly) } & & A & & A \\
\hline & $\mathrm{B}$ & & $\mathrm{B}$ & $\mathrm{B}$ \\
\hline & & BG & BG & \\
\hline \multirow[t]{3}{*}{$\mathrm{CH}$} & $\mathrm{CH}$ & & $\mathrm{CH}$ & $\mathrm{CH}$ \\
\hline & $\mathrm{CZ}$ & & $\mathrm{CZ}$ & \\
\hline & $\begin{array}{l}\mathrm{D} \text { (professional } \\
\text { guidelines (Geyer et al., } \\
\text { 2006)) }\end{array}$ & $\begin{array}{l}\mathrm{D} \text { (professional } \\
\text { guidelines (Geyer et al., } \\
\text { 2006)) }\end{array}$ & $\begin{array}{l}\mathrm{D} \text { (professional } \\
\text { guidelines (Geyer et al., } \\
\text { 2006)) }\end{array}$ & \\
\hline \multirow[t]{4}{*}{ DK } & & DK & & DK \\
\hline & $\mathrm{E}$ & $\mathrm{E}$ & $\mathrm{E}$ & $\mathrm{E}$ \\
\hline & & & EST & EST \\
\hline & $\mathrm{F}$ & & & $\mathrm{F}$ \\
\hline \multirow[t]{11}{*}{ FIN } & FIN & & FIN & \\
\hline & & GR & GR & GR (less severe cases) \\
\hline & & I & I & \\
\hline & IRL & & & IRL \\
\hline & & $\mathrm{L}$ & $\mathrm{L}$ & $\mathrm{L}$ \\
\hline & & & $\mathrm{LT}$ & \\
\hline & & LV & LV (in exceptions) & \\
\hline & $\mathrm{N}$ & & & \\
\hline & & & $\mathrm{P}$ & \\
\hline & & & PL & \\
\hline & RO & RO & $\mathrm{RO}$ & \\
\hline \multirow[t]{2}{*}{$\begin{array}{l}\text { SK (if it helps in } \\
\text { regaining social } \\
\text { functionality) }\end{array}$} & & SK & & \\
\hline & & & SLO & SLO \\
\hline
\end{tabular}


are all three drugs offered in routine treatment in any one country, and the length of recommended treatment, dose, countries. Thus, while the big picture presented in the guidelines, or practiced in the countries without guidelines, is quite similar, there is both between- and within-country variation in the EU (see Appendix 2 with country reports).

\section{Discussion}

Overall, reduction of drinking has become more and more accepted as a treatment objective, secondary or-less often-alternative to abstinence, in guidelines but even more in practice, as several surveys among treatment providers in Belgium, Finland, France and Switzerland show (http://www.belspo.be/belspo/home/publ/pub_ostc/ Drug/rDR25r_en.pdf; Klingemann, Rosenberg, Schweizer, \& Schatzmann, 2005; Luquiens et al., 2011). For instance, a recent Finnish survey among GPs and other doctors ( $n=$ 568) treating $\mathrm{AD}$ (Alho, H., unpublished) showed that $73.1 \%$ of the doctors accept reduced drinking as a treatment goal, and $86.4 \%$ have been using it as a treatment goal. This is encouraging, as reduction of drinking seems to have been an important treatment goal for patients with $\mathrm{AD}$ for some time (see Bigelow, Cohen, Liebson, \& Faillace, 1972; for a more current study see Heather, Adamson, Raistrick, \& Slegg, 2010).

This acceptance of reduced consumption and controlled drinking in guidelines and by practitioners is based partly on the relatively good treatment outcomes of controlled drinking studies (Miller et al., 2003; Saladin \& Santa Ana, 2004; Walters, 2000) and partly on the realities of practical treatment, when it is often found that a certain proportion of patients with $\mathrm{AD}$ do not achieve abstinence, but are able to reduce their alcohol consumption significantly. Some of these clients also do not wish to achieve total abstinence, for various reasons (Heather et al., 2010). However, treatment goals change during treatment to a considerable degree (Ambrogne, 2002). Thus, given the low treatment rate, it seems to be more important to get people into treatment in the first place (Owen \& Marlatt, 2001; Rehm et al., 2012).

At this point, the question arises: How much of an impact do national guidelines have on treatment practice? Clearly, as they are written and composed by local professional organizations, they are to some extent based on, or influenced by, clinical practice. Also, where guidelines are absent, as is the case in Slovenia (Susic, Kersnik, \& Kolsek, 2010), they seem to be missed by practitioners. However, that does not mean that where guidelines exist, they are fully applied in all cases, or that practitioners claiming to use guidelines actually do so and do not have concerns about them (Carlsen \& Bringedal, 2011; Ulvenes, Aasland, Nylenna, \& Kristiansen, 2009; for a more general discussion see Broekaert, Autrique, Vanderplasschen, \& Colpaert, 2010). Overall, in our survey, we probably should have insisted on collecting more information on the practice of treatment within the countries in which guidelines existed.

\section{Limitations}

This study also had limitations. The search strategies may have missed some guidelines, as many of them have not been published in the academic literature, and we had no systematic measure for the level of implementation of guidelines, which may vary between countries. Furthermore, the sampling of experts may have resulted in some bias, as we heavily relied on experts who had published on the topic of ADT. We hope most of these limitations can be overcome by reactions to this publication. Despite these limitations, this first overview of practices in ADT showed important similarities and discrepancies between EU countries, and hopefully will help in improving treatment of $\mathrm{AD}$ in this region.

\section{Acknowledgements}

The authors wish to thank Drs. K. Brzózka (Poland), S. Butler (Ireland), A. Chileva (Bulgaria), L. Christodoulou (Cyprus), C. Drummond (UK), S. Florescu (Romania), P. Gheorghe (Romania), E. Hriscu (Romania), P. Hentgen (Luxembourg), A. Hope (Ireland), R. Kalda (Estonia), T. Koos (Hungary), J. Körkel (Germany), I. Landsmane (Latvia), A.R. Lingford-Hughes (UK), D. Neto (Portugal), H. Ólafsdóttir (Iceland), D. Raistrick (UK), R. Room (Sweden), K. Rosikova (Slovakia), I. Rossow (Norway), J. Storbjörk (Sweden), E. Subata (Lithuania), K. Stenius (Sweden), A. Uchtenhagen (Switzerland), W. van den Brink (Netherlands), E. Vandlik (Hungary), and three experts who wish to remain anonymous, for providing valuable insights into the guidelines for, and practice of, alcohol dependence treatment in their countries and/or for referring us to other specialists for their countries. The study was financially supported by an unrestricted grant of H.Lundbeck A./S. The authors have the sole responsibility for the content

\section{References}

Alonso, J., Angermeyer, M. C., Bernert, S., Bruffaerts, R., Brugha, T. S., Bryson, H. . . Vollebergh, W. A. M. (2004). Use of mental health services in Europe: Results from the European Study of the Epidemiology of Mental Disorders (ESMeD) project. Acta Psychiatrica Scandinavica, 109, 47-54.

Ambrogne, J. A. (2002). Reduced-risk drinking as a treatment goal: What clinicians need to know. Journal of Substance Abuse Treatment, 22, 45-53.

Ameisen, O. (2008). The end of my addiction. New York, NY, United States: Farrar Straus Giroux.

Anderson, P., Gual, A., \& Colom, J. (2005). Alcohol and primary health care: Clinical guidelines on identification and brief interventions. Barcelona, Spain: Department of Health, Government of Catalonia.

Autrique, M., Vanderplasschen, W., Broekaert, E., \& Sabbe, B. (2009). Practitioners' attitudes concerning evidence-based guidelines in Belgian substance abuse 
treatment. European Addiction Research, 15, 47-55. doi:10.1159/000173009

Baldacchino, A. M. (1991). Alcohol and alcohol problems research 17. Malta. British Journal of Addiction, 86, 951-956. doi:10.1111/j.1360-0443.1991.tb01855.x

Bigelow, G., Cohen, M., Liebson, I., \& Faillace, L. A. (1972). Abstinence or moderation? Choice by alcoholics. Behaviour Research and Therapy, 10, 209-214. doi:10.1016/0005-7967(72)90037-X

Broekaert, E., Autrique, M., Vanderplasschen, W., \& Colpaert, K. (2010). 'The human prerogative': A critical analysis of evidence-based and other paradigms of care in substance abuse treatment. Psychiatric Quarterly, 81, 227-238. doi:10.1007/ s11126-010-9132-4

Carlsen, B., \& Bringedal, B. (2011). Attitudes to clinical guidelines-do GPs differ from other medical doctors? British Medical Journal Quality and Safety, 20, 5862. doi:10.1136/bmjqs.2009.034249

Cyprus Anti-Drugs Council. (2010). National treatment guideline. Nicosia, Cyprus: Author

Deutsche Rentenversicherung Bund. (2009). RehaTherapiestandards Alkoholabhängigkeit - Pilotversion [Therapy standards for the rehabilitation of alcohol dependence - Pilot version]. Berlin, Germany: Deutsche Renten-versicherung Bund.

Dezetter, A., Briffault, X., Alonso, J., Angermeyer, M. C., Bruffaerts, R., de Girolamo, G., . . . Kovess-Masfety, V. (2011). Factors associated with use of psychiatrists and nonpsychiatrist providers by ESEMeD respondents in six European countries. Psychiatric Services, 62, 143-151. doi:10.1176/appi.ps.62.2.143

Drummond, C., Gual, A., Goos, C., Godfrey, C., Deluca, P., Von Der Goltz, C., . . . Kaner, E. (2011). Identifying the gap between need and intervention for alcohol use disorders in Europe. Addiction, 106, 3136.

Dunzinger, E. (2005). Therapie des Alkoholabusus [Therapy of alcohol use disorders.]. (DFP). Retrieved from http://www.webcitation.org/609QJidS9.

Field, M. J., \& Lohr, K. N. (1992). Guidelines for clinical practice: From development to use. Washington, DC, United States: National Academy Press.

Geyer, D., Batra, A., Mueller-Fahrnow, W., MuellerMohnssen, M., Soyka, M., \& Spyra, K. (2006). AWMF Leitlinie: Postakutbehandlung alkoholbezogener Stoerungen [AWMF Guideline: Post-actue treatment of alcohol abuse and dependence]. Sucht, 52, 8-34.

Guardia Serecigni, J., Arriero, M. A., Pastor, F. P., Menéndez, G. F., \& Guillamón, M. C. I. (2008). Alcoholismo. Guías clínicas socidrogalcohol basadas en la evidencia científic (2a edición) [Alcoholism. Clinical guidelines based on scientific evidence]. Barcelona, Spain: Socidraogalcohol.

Gustavsson, A., Svensson, M., Jacobi, F., Allgulander, C., Alonso, J., Beghi, E., ...Oleson, J. (2011). Cost of disorders of the brain in Europe 2010. European Neuropsychopharmacology, 21, 718-779. doi:10. 1016/j.euroneuro.2011.08.008
Hamburg, S. (1975). Behavior theraphy in alcoholism. A critical review of broad-spectrum approaches. Journal of Studies on Alcohol, 36, 69-87.

Heather, N., Adamson, S. J., Raistrick, D., \& Slegg, G. P.(2010). Initial preference for drinking goal in the treatment of alcohol problems: I. Baseline differences between abstinence and non-abstinence groups. Alcohol and Alcoholism, 45, 128-135. doi:10.1093/alcalc/agp096

Hillemacher, T., \& Bleich, S. (2008). Neurobiology and treatment in alcoholism-recent findings regarding Lesch's typology of alcohol dependence. Alcohol and Alcoholism, 43, 341-346. doi:10.1093/alcalc/agn016

Intercollegiate Guidelines Network. (2003). The management of harmful drinking and alcohol dependence in primary care: A national clinical guideline. Edinburgh, Scotland: Scottish Intercollegiate Guidelines Network.

Kienast, T., \& Heinz, A. (2005). Therapy and supportive care of alcoholics: Guidelines for practitioners. Digestive Diseases, 23, 304-309. doi:10.1159/ 000090178

Klingemann, H., Rosenberg, H., Schweizer, B., \& Schatzmann, S. (2005). Kontrolliertes Trinken als Behandlungsziel - Gesamtschweizerische Umfrage zur Akzeptanz und Praxisumsetzung [Controlled drinking as a therapy goal. A Swiss survey on the acceptance and translation into clinical practice]. Bern, Germany: Berner Fachhlochshule Soziale Arbeit.

Klingemann, H., Takala, J. P., \& Hunt, G. (1992). Cure, care, or control: Alcoholism treatment in sixteen countries. Albany, NY, United States: State University of New York Press.

Körkel, J. (2006). Behavioural self-management with problem drinkers: One-year follow-up of a controlled drinking group treatment approach. Addiction Research and Theory, 14, 35-49. doi:10.1080/ 16066350500489253

Leentjens, A. F. G., \& Diefenbacher, A. (2006). A survey of delirium guidelines in Europe. Journal of Psychosomatic Research, 61,123-128. doi:10.1016/ j.jpsychores.2006.01.009

Lesch, O. M., \& Walter, H. (1996). Subtypes of alcoholism and their role in therapy. Alcohol and Alcoholism, 31, 63-67.

Lingford-Hughes, A. R., Welch, S., \& Nutt, D. J. (2004). Evidence-based guidelines for the pharmacological management of substance misuse, addiction and comorbidity: Recommendations from the British Association for Psychopharmacology. Journal of Psychopharmacology, 18, 293-335. doi:10.1177/ 0269881104048516

Lingford Hughes, A. R., Welch, S., Peters, L., Nutt, D. J., British Association for Psychopharmacology, \& Expert Reviewers Group. (2012). BAP updated guidelines: Evidence-based guidelines for the pharmacological management of substance abuse, harmful use, addiction and comorbidity: Recommendations from BAP. Journal of Psychopharmacology, 26, 899-952. doi:10.1177/ 0269881112444324. 
Luquiens, A., Reynaud, M., \& Aubin, H. J. (2011). Is controlled drinking an acceptable goal in the treatment of alcohol dependence? A survey of French alcohol specialists. Alcohol and Alcoholism, 48, 586-591. doi:10.1093/alcalc/agr083

Mäkelä, K., Arminen, I., Bloomfield, K., Eisenbach-Stangl, I., Bergmark, K. H., Kurube, N., . . . Zielinski, A. (1996). Alcoholics Anonymous as a mutual-help movement: A study in eight societies. Madison, WI, United States: University of Wisconsin Press.

Mäkelä, K., \& Säilä, S. L. (1987). The distribution of alcohol-related overnight stays among different authorities in Finland, 1960-1980. Contemporary Drug Problems, 14, 125-136.

Martin, G., \& Rehm, J. (2011). The effectiveness of psychosocial modalities in the treatment of alcohol problems in adults: A review of the evidence. Canadian Journal of Psychiatry, 57, 350-358.

Meyer, T. (2009). Kontrolliertes Trinken - Stand der Debatte in der Schweiz. [Controlled drinking - The current debate in Switzerland.] Abhaengigkeiten, 1/09, 17-29.

Miller, W. R., Wilbourne, P. L., \& Hettema, J. E. (2003). What works? A summary of alcohol treatment outcome research. In R. K. Hester \& W. R. Miller (Eds.), Handbook of alcoholism treatment approaches (Vol. 3, pp. 13-63). Boston, MA, United States: Allyn and Bacon.

Multidisciplinaire Richtlijnontwikkeling G. Z. Z. (2009). Multidisciplinaire richtlijn. Stoornissen in het gebruik van alcohol: richtlijn voor de diagnostiek en behandeling van volwassen patie"nten met een stoornis in het gebruik van alcohol [Multidisciplinary guidelines. Impairment resulting from the use of alcohol: Guidelines for the diagnosis and treatment of adult patients with alcohol use disorders]. Utrecht, The Netherlands: Trimbos-instituut.

Neto, D., Lambaz, R., Aguiar, P., \& Chick, J. (2008). Effectiveness of sequential combined treatment in comparison with treatment as usual in preventing relapse in alcohol dependence. Alcohol and Alcoholism, 43, 661-668. doi:10.1093/alcalc/agn075

Neto, D., Lambaz, R., \& Tavares, J. (2007). Compliance with aftercare treatment, including disulfiram, and effect on outcome in alcohol-dependent patients. Alcohol and Alcoholism, 42, 604-609. doi:10.1093/ alcalc/agm062

National Institute for Health and Clinical Excellence (NICE). (2011). Alcohol use disorders: Diagnosis, assessment and management of harmful drinking and alcohol dependence. London, United Kingdom: Author.

Owen, P., \& Marlatt, G. A. (2001). Should abstinence be the goal for alcohol treatment? American Journal of Addiction, 10, 289-291.

Raboch, J., Anders, M., Hellerová, P., \& Uhlíková, P. (2010). Psychiatrie: Doporuèené postupy psychiatrické péèe III [Psychiatry: Recommended practices in psychiatric care]. Brno, Czech Republic: Tribun, European Union.

Raistrick, D., Heather, N., \& Godfrey, C. (2006). Review of the effectiveness of treatment for alcohol problems.
London, United Kingdom: National Treatment Agency for Substance Abuse.

Rehm, J., Mathers, C., Popova, S., Thavorncharoensap, M., Teerawattananon, Y., \& Patra, J. (2009). Global burden of disease and injury and economic cost attributable to alcohol use and alcohol use disorders. Lancet, 373, 2223-2233. doi:10.1016/S01406736(09)60746-7

Rehm, J., Rehm, M. X., Shield, K. D., Gmel, G., \& Gual, A. (2013). Alcohol consumption, alcohol depend-ence and related harms in Spain, and the effect of treatment-based interventions on alcohol dependence. Adicciones, 25, 11-18. Retrieved from http://www.adicciones.es/files/011018\%20SHIELD_con\%20apendice.pdf

Rehm, J., Shield, K. D., Rehm, M. X., Gmel, G., \& Frick, U. (2013). Modelling the impact of alcohol dependence on mortality burden and the effect of available treatment interventions in the European Union. European Neuropsychopharmacology, 23, 8997. [Epub ahead of print]. doi:10.1016/j.euroneuro. 2012.08.001

Rehm, J., Shield, K. D., Rehm, M. X., Gmel, G., \& Frick, U. (2012). Alcohol consumption, alcohol dependence, and attributable burden of disease in Europe: Potential gains from effective interventions for alcohol dependence. Toronto, Canada: Centre for Addiction and Mental Health.

Rehm, J., Sulkowska, U., Manczuk, M., Boffetta, P., Powles, J., Popova, S., \& Zatonski, W. (2007). Alcohol accounts for a high proportion of premature mortality in central and eastern Europe. International Journal of Epidemiology, 36, 458-467. doi:10.1093/ ije/dyl294

Rehm, J., Zatonski, W., Taylor, B., \& Anderson, P. (2011). Epidemiology and alcohol policy in Europe. Addiction, 106(Suppl.1), 11-19. doi:10.1111/j.13600443.2010.03326.x

Rolland, B., Bordet, R., \& Cottencin, O. (2012). Alcoholdependence: The current French craze for baclofen. Addiction, 107, 848-849.

Rus-Makovec, M., \& Eebasek-Travnik, Z. (2008). Longterm abstinence and well-being of alcohol-dependent patients after intensive treatment and aftercare telephone contacts. Croation Medical Journal, 49, 763-771. doi:10.3325/cmj.2008.49.763

Saladin, M. E., \& Santa Ana, E. J. (2004). Controlled drinking: More than just a controversy. Current Opinion in Psychiatry, 17, 175-187.

Schmidt, P., Köhler, J., \& Soyka, M. (2008). Leitlinien in der stationären Rehabilitation Alkoholkranker. Eine Übersicht [Guidlines for inpatient rehabilitation of people with alcohol dependence. An Overview]. Nervenheilkunde, 27, 40-46.

Seifertová, D., Prasko, J., Horáèek, J., \& Höschl, C. (2008). Postupy $v$ léèbì psychickych poruch. [Procedures for the treatment of mental disorders]. Prague, Czech Republic: Academia Medica Pragensis.

Sikic, B. I., Walker, R. D., \& Peterson, D. (1972). An evaluation of a program for the treatment of alcoholism in Croatia. International Journal of Social 
Psychiatry, 18, 171-181. doi:10.1177/00207640 7201800303

Société Française d'alcoologie. (2001). Recommandations pour la pratique clinique. Les conduites d'alcoolisation. Lecture critique des classifications et définitions. Quel objectif thérapeutique? Pour quel patient? Sur quels critères? [Guidelines and recommendations for clinical practice of alcohol use disorders. A critical examination of classifications and defintions. Which therapeutic objective? For which patient? Based on which criteria?]. Alcoologie et Addictologie, 23, 1s-76s.

Stroup, D. F., Berlin, J. A., Morton, S. C., Olkin, I., Williamson, G. D., \& Rennie, D. (2000). Metaanalysis of observational studies in epidemiology: A proposal for reporting. The Journal of the American Medical Association, 283, 2008-2012. doi:10.1001/ jama.283.15.2008

Susic, T. P., Kersnik, J., \& Kolsek, M. (2010). Why do general practitioners not screen and intervene regarding alcohol consumption in Slovenia? A focus group study. Wien Klin Wochenschr, 122, 68-73. doi:10.1007/s00508-010-1335-z

Uhl, A., Bachmayer, S., Kobrna, U., Puhm, A., Springer, A., Kopf, N., . . . Musalek, M. (2009). Handbuch: Alkohol - Österreich: Zahlen, Daten, Fakten, Trends 2009. dritte überarbeitete und ergänzte Auflage [Handbook: Alcohol Austria: Numbers, data, facts, trends 2009. ( $3^{\text {rd }}$ ed.)]. Wien, Austria: Bundesministerium für Gesundheit.

Uhl, A., Bachmayer, S., Puhm, A., Kobrna, U., \& Musalek, M. (2011). Handbuch Alkohol - Österreich. 4th edition. Band 2: Einrichtungen 2011 [Handbook Alcohol Austria: Treatment facilities (Vol. 2, $4^{\text {th }}$ ed.)]. Wien, Austria: Bundesministerium für Gesundheit.
Ulvenes, L. V., Aasland, O., Nylenna, M., \& Kristiansen, I. S. (2009). Norwegian physicians' knowledge of and opinions about evidence-based medicine: Crosssectional study. PLoS ONE, 4(11), e7828. doi:10.1371/journal.pone.0007828

Walters, G. D. (2000). Behavioral self-control training for problem drinkers: A meta-analysis of randomized control studies. Behavior Therapy, 31, 135-149. doi: 10.1016/S0005-7894(00)80008-8

Wittchen, H. U., Jacobi, F., Rehm, J., Gustavsson, A., Svensson, M., Jönsson, B., . . . Steinhausen, H. C. (2011). The size and burden of mental disorders and other disorders of the brain in Europe 2010. European Neuropsychopharmacology, 21, 655-679. doi: 10.1016/j.euroneuro.2011.07.018

World Health Organization. (2006). Framework for alcohol policy in the WHO European Region. Copenhagen, Denmark: Author.

World Health Organization. (2008). The global burden of disease: 2004 update. Geneva, Switzerland: Author.

World Health Organization. (2010). Global strategy to reduce the harmful use of alcohol. Geneva, Switzerland: Author.

\section{Appendices}

\section{Appendix 1}

Abstinence as ultimate goal in National treatment guidelines

\begin{tabular}{ll}
\hline Country & Is abstinence the ultimate treatment goal? \\
\hline Cyprus & Yes \\
France & Yes \\
Germany & Yes \\
Hungary & Yes \\
Iceland & Yes \\
Netherlands & No \\
Poland & Yes \\
Slovenia & Yes \\
Sweden & One possible ultimate goal \\
United Kingdom & One possible ultimate goal \\
\hline
\end{tabular}




\section{Appendix 2}

\section{Country reports}

\section{AUSTRIA}

In Austria, no general guidelines for ADT are available, but based on information provided by experts, it is safe to assume that ADT for rehabilitation and re-entering the workforce is mainly geared towards abstinence, as is the case in the other German-speaking regions. Abstinence is also seen as the main goal for other ADTs. However, reduced consumption/controlled drinking is accepted as well. First, if abstinence is not possible, reduction of consumption is acceptable as either the ultimate or an intermediate goal. Secondly, there is a lot of emphasis on voluntary treatment in Austria (http://www.wecarelife.at/gesundheit-medizin/ alkoholismus/behandlung-und-therapie/), and if the client with $\mathrm{AD}$ does not accept an abstinence goal, reduced consumption/ controlled drinking is an option (http://www.wecarelife.at/ gesundheit-medizin/alkoholismus/behandlungsziel-abstinenz-vskontrolliertes-trinken/). In Austria, the typology of Lesch and Walter (1996), which has received some corroboration from neurobiology (Hillemacher \& Bleich, 2008), is prominent. According to this typology, not all people with AD must remain abstinent, and this may also impact on the relative acceptance of reduced consumption/controlled drinking goals.

While there are no general guidelines, there are guidelines that specifically address ADT and the elderly (Dunzinger, 2005). It is notable that in these guidelines, abstinence is not the ultimate goal for patients. Rather, the reduction of risks is the primary goal, and, as specified in the guidelines, this can be achieved by reducing alcohol consumption. While these guidelines mention only psychotherapy in general, without specifying recommended approaches, acamprosate and naltrexone are specifically mentioned as types of pharmacotherapy.

ADT for the general population is similar. In addition to the usual forms of psychotherapy, acamprosate, naltrexone (including extended-release naltrexone), and disulfiram are mentioned; the latter is not used widely and is only recommended with limitations, because of side effects.

Aftercare is a strong component of ADT in Austria, with self-help groups being an integral part. The two largest groups hereAlcoholics Anonymous (Mäkelä et al., 1996) and the Blue Crossare both abstinence oriented (Uhl et al., 2009; Uhl, Bachmayer, Puhm, Kobrna, \& Musalek, 2011).

\section{BELGIUM}

Belgium is currently developing national guidelines concerning ADT (http://www.belspo.be/belspo/home/publ/pub_ostc/Drug/ rDR25r_en.pdf). Also, according to a survey of treatment providers, provider-specific guidelines already exist (Autrique, Vanderplasschen, Broekaert, \& Sabbe, 2009).

In practice, based on this survey and other publications, abstinence is generally the ultimate treatment goal. However, in less severe cases of $\mathrm{AD}$, reduction of consumption can be a treatment option. Furthermore, treatment may begin with an intermediate goal of reduced/controlled drinking, in the sense of harm reduction. This would also include limiting alcohol use to low-risk situations (e.g., at home).

Patients with $\mathrm{AD}$ are managed with psychotherapy and possibly pharmacotherapy. Psychotherapy includes individual counseling, family-oriented interventions, psycho-education, and brief interventions. Flemish agencies often make use of gradual reduction schedules, behavioral and cognitive interventions, coping skills training, psycho-education, and aftercare; institutions in the
Wallon region are also offering psychoanalytically-influenced therapy. When administered, pharmacotherapy is always combined with some form of psychotherapy. Acamprosate is used to maintain abstinence, in association with other therapeutic psychosocial approaches. Disulfiram is less frequently used and should also be combined with a psychosocial approach.

\section{BULGARIA}

Bulgaria is currently developing national guidelines regarding $\mathrm{ADT}$. What we have been able to gather concerning the status quo was from a presentation on the upcoming guidelines given by an expert from Bulgaria (http://ec.europa.eu/health/alcohol/docs/ ev_20100127_co07_en.pdf (archived link: http://www.webcitation. org/5zxeMe4El)). The two main psychotherapeutic treatments administered in Bulgaria are a 12-step type and a bio-psychosocial approach. Both of these treatments are abstinence based, which makes the role of reduced/controlled drinking and its general acceptance unclear.

\section{CYPRUS}

In Cyprus, a set of national guidelines that regulates treatment of all substance abuse problems exists (Cyprus Anti-Drugs Council, 2010). Abstinence is clearly the main treatment goal, as it is mentioned explicitly several times in various treatment protocols as well as implicitly throughout the guidelines. The guidelines also mention that the main goal of therapy is to achieve the greatest degree of health. While this could be achieved by reduced/controlled drinking, such treatment goals are never mentioned in the guidelines.

$\mathrm{AD}$ is treated exclusively by psychotherapy, in outpatient or rehabilitation centers, depending on the severity of the addiction. Psychosocial interventions in Cyprus generally include cognitivebehavioral therapy, relapse preventions strategy, the acquisition of skills to manage situations of potential relapse, motivational enhancement therapy, and interventions in the family.

\section{CZECH REPUBLIC}

The Czech Republic has two sets of professional guidelines for treatment of AD (Raboch, Anders, Hellerová, \& Uhlíková, 2010; Seifertová, Prasko, Horáèek, \& Höschl, 2008). Abstinence is considered the ultimate goal in treatment, whenever possible. However, reduction can be used as an intermediate or even an ultimate goal, depending on the general health of the patient.

In treatment, psychotherapy and pharmacotherapy is used. Common psychotherapeutic measures include brief intervention, motivational therapy, cognitive-behavioral therapy, family therapy, psychodynamic therapy, and interactive group therapy. In addition, the following medication is used: disulfiram, acamprosate, naltrexone, antidepressants, anticonvulsants, antipsychotics, and buspirone.

\section{DENMARK}

Although it does not have cohesive guidelines, Denmark has published a collection of evidence that considers multiple treatment options as viable (http://www.sst.dk/publ/Publ2006/ CEMTV/Alkoholbeh/MTValkoholbehandling.pdf (archived link: http://www.webcitation.org/ 60V14GSeG )). According to this document, treatment is seen as individualized and negotiated between the therapist and the patient. As such, abstinence is not necessarily always the goal and reduced/controlled drinking is accepted as an intermediate and ultimate goal.

Psychotherapy and pharmacotherapy are used to treat AD. Psychotherapeutic treatments include motivational therapy and cognitive-behavioral therapy, as well as community reinforcement strategies. The main medications used are benzodiazepines for withdrawal, and acamprosate and naltrexone for dependence 
treatment-that is, treatment in the post-acute state to decrease the risk of relapse. Supervised disulfiram is also recommended.

\section{ESTONIA}

Estonia has published guidelines on how to treat patients that abuse drugs, without specific mention of ADT (link: http://www.emcdda.europa.eu/attachements.cfm/att_101778_EN_ EE01_alcohol\%20+\%20drugs.pdf ; archived link: http://www. webcitation.org/60WTQhJ3R). In practice, abstinence is the ultimate goal, but reduction of consumption is accepted both as an intermediate goal and as an ultimate goal if the patient requests it. At least one clinic has embraced the Sinclair method (http://www.akliinik.ee/artiklid.htm), where reduction is the ultimate goal.

Treatment of $\mathrm{AD}$ consists mainly of psychotherapy. Psychotherapeutic measures that are used include cognitive behavioral therapy, group therapy, family therapy, and, if deemed necessary and wanted, self-help groups such as Alcoholics Anonymous. Pharmacotherapy consists of antidepressants, benzodiazepine for withdrawal, and disulfiram for rehabilitation and aftercare.

\section{FINLAND}

Finland has evidence-based guidelines for the treatment of AD and AUD, published by the National Medical Association, Duodecim (http://www.kaypahoito.fi/web/kh/suositukset/naytaarti

kkeli/.../ccs00005 archived link: http://www.webcitation.org/ 60Gz8g8rX). Abstinence is generally the ultimate treatment goal for AD. However, in less severe cases, abstinence is usually seen as unrealistic, which makes reduced drinking an acceptable option. Also, reduction is often an intermediate goal for patients with extremely severe $\mathrm{AD}$, in order to bring drinking levels down to a point where they are less potentially threatening to the patient's general health.

Psychotherapy and pharmacotherapy are both used in treatment of AD. Various models of psychotherapy are used, including cognitive behavioral therapy, motivational therapy, Minnesota model type treatment, self-help groups such as Alcoholics Anonymous, and-in private clinics-short-term cognitive behavioral therapy in combination with naltrexone pharmacotherapy. Variants based on principles of the cognitive behavioral approach are often used. The medications used in treatment are disulfiram, naltrexone, acamprosate (under special license in Finland), selective serotonin reuptake inhibitors, topiramate, and in some special cases anti-psychotics.

\section{FRANCE}

In France, there are national guidelines that govern ADT (Société Française d'Alcoologie, 2001). Abstinence is clearly the ultimate goal, as withdrawal is seen as a necessary step in treatment. Reduction of alcohol intake is seen as neither an ultimate nor an intermediate goal. However, the overall goal of therapy is seen as an improvement in well-being, as well as familial and social integration. This objective may lead about $50 \%$ of alcohol therapists, in practice, to accept controlled drinking as an alternative goal-most often in cases where the patient chooses this goal, but also in some cases where dependence is less severe (Luquiens et al., 2011). Also, according to the same survey, an even larger proportion of therapists practiced controlled drinking.

Psychotherapy and pharmacotherapy are combined in both inpatient and outpatient treatment. While there is some remaining influence of psychoanalysis, the most recommended procedure is cognitive-behavioral therapy. Also recommended are group therapy and self-help groups, and bringing significant others in therapy. In terms of medication, acamprosate (recommended duration one year), naltrexone (three months), and disulfiram are recommended and used. Benzodiazepanes are used in detoxification and, in general, to prevent and treat withdrawal on a short-term basis. Prescriptions of high dosages of off-label baclofen have become popular since the publication of a bestselling memoir about a doctor's experience with the drug (Ameisen, 2008; Rolland, Bordet, \& Cottencin, 2012).

\section{GERMANY}

ADT is governed by different guidelines in Germany, as listed in Table 1a and 1b (Schmidt, Köhler, \& Soyka, 2008).

The most important funder of in- and outpatient treatment of $\mathrm{AD}$ in Germany is the German Pension Fund (Deutsche Rentenversicherung), and this organization issued professional guidelines for quality assurance purposes as a precondition for coverage of costs (Rentenversicherung Bund, 2009). The main objective of these guidelines is to achieve a sustainable reintegration of the people who are threatened by a reduction in earning capacity (Rentenversicherung Bund, 2009). Even though it is not made explicit in the document, abstinence is the main goal; this is also clearly established in the clinical practice of professional rehabilitation.

The professional guidelines (Geyer et al., 2006) of the German Society for Addiction Research and the German Society for Psychiatry, Psychotherapy and Neurology are more explicit. These guidelines also have abstinence as the general objective of ADT, but clearly specify that reduction of consumption should be a goal for those who cannot achieve abstinence. It is clearly stressed that reduction of drinking means risk reduction with respect to the somatic and mental consequences of $\mathrm{AD}$. Reduction of drinking can also be an intermediate goal.

Finally, there are national legally binding guidelines for psychotherapy (http://www.kvwl.de/arzt/recht/kbv/richtlinien/ richtl_psycho.pdf). These guidelines were recently revised to better cover the remuneration of treatment for substance disorders. The ultimate goal specified in these guidelines, which cover only the psychotherapeutic part of ADT, is abstinence.

Behavioral-based "controlled drinking” therapy (Körkel, 2006) is also offered for people with AD in Germany, albeit not in the rehabilitation system. There is also an organization whose chief goal is to promote controlled drinking as a treatment option.

Overall, however, most ADT in Germany is abstinence oriented, as the goal of abstinence is a pre-condition for remuneration of therapy in most cases. With respect to types of treatment, psychosocial therapy is the primary form of psychotherapy (although ergotherapy and sociotherapy exist), which includes cognitive behavioral treatment in its various forms, psychoeducation, social competence improvement training, and family therapies. A different form of cognitive behavioral approach is the aforementioned controlled drinking approach (http://www.kontrolliertes-trinken.de/kontrolliertes-trinken/de/). Acamprosate is the most commonly used compound in Germany (it is administered as part of the treatment for one year); also used are naltrexone and disulfiram, athough since 2011 the latter no longer has a license, as the producer decided not to reapply for economic reasons.

\section{GREECE}

Greece does not have national guidelines for ADT. However, according to expert opinion, abstinence generally seems to be the ultimate goal in treatment, with reduced/controlled drinking being an option in case abstinence fails and as an intermediate goal. It can also be an option if the patient requests it in less severe cases. 
Cognitive-behavioral therapy is the main psychotherapeutic treatment, sometimes combined with family or partner-treatment approaches. Medication is used for only part of the ADT process, mainly naltrexone, usually for three months, and then to be continued after an evaluation by the treating physician. Disulfiram is also used rarely.

\section{HUNGARY}

Hungary has a set of guidelines http://www.eum.hu/ egeszsegpolitika/minosegfejlesztes/pszichiatria (archived link: http://www.webcitation.org/60IYVTHVD ) for ADT. According to these guidelines, abstinence is always the first treatment goal. However, reduction of consumption can be acceptable either when abstinence fails to be reached, or in severe cases, to reduce the risk to general health.

For patients with $\mathrm{AD}$, psychotherapy and pharmacotherapy are used together (psychotherapy is rarely used alone). Depending on the patient's health status and co-operation, CBT, MET, problemfocused therapy, and group therapy, as well as family and couple therapy, are used. In addition to this, the medications used are disulfiram, acamprosate, and naltrexone for relapse treatment. Carbamazepine, diazepam, and other benzodiazepines are used to reduce withdrawal symptoms and anxiety. Also, in some cases SSRIs are used for relapse prevention. If psychotic symptoms are present, antipsychotics are used.

\section{ICELAND}

Iceland has national guidelines for ADT, influenced in part by the Scottish guidelines (Intercollegiate Guidelines Network, 2003). These guidelines (http://landlaeknir.is/pages/1210 ; archived link: http://www.webcitation.org/60V8ixAJp) stress that abstinence is the ultimate treatment goal, with reduced/controlled drinking not being a treatment option.

Psychotherapy is used to treat $\mathrm{AD}$, with pharmacotherapy administered additionally in co-morbid cases (antidepressants and antipsychosis medication). The various different measures of psychotherapy include Minnesota model 12-step treatment, brief interventions, motivational interviewing, and cognitive-behavioral therapy, as well as family-oriented treatment.

\section{IRELAND}

Ireland does not have a set of national guidelines governing ADT, but abstinence is usually the ultimate goal in treatment, especially in inpatient treatment (in both Minnesota-model 12-step treatment programs and psychiatric institutions). However, patients in primary care settings can have the goal of controlled drinking, if their dependence is mild.

Psychotherapy is mainly used in treatment of $\mathrm{AD}$, and, in residential settings, is mainly of the Minnesota model type. Community-based treatment often include motivational interviewing, cognitive behavioral therapy, and-in more recent times-the cognitive reinforcement approach. An approach called "behavioral self control training" is considered most effective for those patients with a moderation goal. AA is the most common form of aftercare.

Pharmacotherapy is generally the last resort, as skepticism regarding drug therapy is prevalent in the country. When used, medication includes acamprosate and disulfiram.

\section{ITALY}

Italy does not have national guidelines for ADT. There is, however, a clear common understanding regarding $\mathrm{ADT}$ in the country. Generally, abstinence is the ultimate and only goal; however, when abstinence cannot be achieved, reduction of drinking is a tolerated outcome, even when the type of treatment is clearly abstinence based.

Both psycho- and pharmacotherapy are used for ADT in Italy (although pharmacotherapy is only used in about $30 \%$ of cases, according to a government report). Psychotherapy includes individual or family counseling, social worker interventions, and group therapy. When pharmacotherapy is administered, the types of drugs used are disulfiram, naltrexone (very rarely), and chlordiazepoxide, the latter mainly in detoxification. Gammahydroxibutyrate is also used for detoxification in hospitals.

It is commonly the case that the patient is also part of a support group, such as AA or a Hudolin group (Sikic et al., 1972). Even though both groups are abstinence oriented, they tend to tolerate participation of people who fail to abstain.

\section{LATVIA}

Latvia does not have national guidelines governing ADT, but professional guidelines do exist. While abstinence is generally the ultimate goal in treatment, reduced consumption is accepted as a goal for people who fail with abstinence, or as an intermediate goal, albeit by a minority of treatment providers only. In addition to psychotherapy - with specific treatment standards issued by the Ministry of Health for motivational therapy, Minnesota 12-step therapy, and relapse prevention therapy-there is pharmacotherapy, including mainly disulfiram and naltrexone. For disulfiram, there are treatment standards specifically for implantation. Acamprosate is used only sparingly. In addition to outpatient programs, there are inpatient rehabilitation programs of three, six or 12 months.

\section{LITHUANIA}

Lithuania does not have national guidelines for ADT. However, based on a survey of experts, we have been able to clarify the status quo regarding ADT in the country. While abstinence is generally the ultimate goal, reduced consumption/controlled drinking is accepted as an intermediate goal.

In terms of treatment specifics, the Minnesota 12-step model and group therapy are frequently used, with pharmacotherapy being added to treatment in co-morbid cases-mainly naltrexone and disulfiram.

\section{LUXEMBOURG}

Luxembourg is currently developing a national set of guidelines regarding ADT, which will be part of a National Alcohol Plan, in accordance with WHO global and regional strategy and EU recommendations (World Health Organization, 2006, 2010) (http://europa.eu/legislation_summaries/public_health/health_ determinants_lifestyle/c11564b_en.htm). A draft introduction to these guidelines has already been published (http://www.ms. public.lu/fr/ministere/cns2006-2010/2010/05-Paul-Hentgen-intro. pdf; archived link: http://www.webcitation. org/60S96m0fZ), and provides a good idea of ADT in the country. Abstinence is generally considered the main goal in ADT. However, other goals, like reduction of drinking, are possible in specific contexts-for example, as an intermediate goal in harm reduction and controlled drinking approaches for chronic, multiply-handicapped dependents on psychotropic substances. In this sense, reduced drinking can be seen as alternative for alcohol-dependent people who cannot or do not want to abstain, and it is seen as a potential interim goal on the way to abstinence.

Pharmacotherapy is used in withdrawal management. Benzodiazepines and vitamin B complex are generally used for non-complicated withdrawals, if there is no co-morbidity. During the post-acute phase and aftercare, the focus is on psychotherapy (sometimes sociotherapy), in combination with medication, if 
indicated (e.g., for co-morbidity or relapse prevention). There are no recommendations for psychotherapy. Modalities depend on the institutional context and the training of professionals; among the most common are motivational interviewing, cognitive-behavioral therapy, psychodynamic approaches, family and group therapy. There are also no recommendations for pharmacotherapy for the post-acute phase for relapse prevention: sometimes disulfiram or acamprosate are used, marginally also naltrexone or lioresal.

\section{MALTA}

Malta has not published official guidelines for ADT. However, the website of the Maltese National Agency against Drug and Alcohol abuse (http://www.sedqa.gov.mt/), as well as an early article (Baldacchino, 1991), give an idea of the status quo in the country. Abstinence is clearly the ultimate goal in treatment, with reduction of alcohol consumption explicitly rejected as a treatment goal. Treatment seems to be influenced by Minnesota-type treatment, which states that it is impossible for a person who is alcoholic to drink reduced amounts of alcohol. There is no mention of pharmacotherapy on the government website; however, the earlier article (Baldacchino, 1991) mentions disulfiram as an aid to psychotherapy. Also, self-help groups (mainly AA) exist and are frequently used in treatment.

\section{THE NETHERLANDS}

The Netherlands have a set of national guidelines that governs ADT (Multidisciplinaire Richtlijnontwikkeling, 2009). The guidelines propose four distinct treatment goals, which can be combined or used as intermediate goals: detoxifications and treatment of withdrawal symptoms, abstinence, reduction of alcohol consumption, and reduction of alcohol-related problems. The guidelines also identify specific patient types that would benefit from controlled/reduced drinking. Therefore, reduced drinking can be either an intermediate or an ultimate treatment goal, depending on the type and severity of the alcohol disorder (reduced/controlled drinking is thought to be a more suitable treatment goal for patients with relatively mild AD).

Psychotherapy is generally used to treat $A D$, with pharmacotherapy used on patients with insufficient improvement. Usually, the psychotherapy administered is a combination of motivational enhancement therapy and cognitive-behavioral therapy. Another option sometimes used is a communityreinforcement approach. About $30 \%$ of patients receive some kind of pharmacotherapy. The main medications that are used are disulfiram, naltrexone, and acamprosate. Sometimes, physicians will also prescribe either topiramate (100-300 mg) or baclofen (30$90 \mathrm{mg})$.

\section{NORWAY}

There are no national guidelines for ADT in Norway. Reduced drinking seems to be an acceptable treatment option only in less severe cases of AD. Psychotherapy and pharmacotherapy are combined in some ADT, with the former mainly consisting of cognitive-behavioral therapy. The medications being used are disulfiram and acamprosate.

\section{POLAND}

In Poland, a set of national guidelines (http://fas.nazwa.pl/ parpa_en/images/stories/ACT.pdf) governing ADT exists. These guidelines specify abstinence (specifically "sustained abstinence") to be the ultimate goal in any dependence treatment. The guideline does not mention reduction/controlled drinking at all, stating that the other goals of therapy are the improvement of the patient's mental and physical condition, and the development of skills needed by the patient to resolve emotional and social problems. One can argue that reduced/controlled drinking can help in achieving these goals, so, implicitly, an intermediate goal of reduced/controlled drinking would not be out of question.
Furthermore, key experts in the field have suggested the explicit inclusion of reduced or controlled drinking in ADT.

Psychotherapy is the main form of treatment, supported by pharmacotherapy, if needed. Psychotherapeutic treatment programs are mainly based on the behavioral and cognitive therapy approach and the ideas and experiences of the AA community. Therapy usually lasts from 12 to 24 months (usually, six to eight weeks in 24-hour clinics and day-only clinics, followed by one to two years in outpatient clinics) and includes 240 hours of group and 50 hours of individual therapy.

Pharmacotherapy is not as commonly used as in other countries. Disulfiram is the most common drug administered, due to the lower price. Acamprosate is also used, but is less popular due to its higher price. Naltrexone is not commonly available throughout Poland, even though it is recommended in treatment. For aftercare, clients are usually referred to support groups such as AA.

\section{PORTUGAL}

Portugal has no national guidelines for ADT. Most treatment is abstinence-oriented, and reduction of consumption/controlled drinking is usually not an accepted treatment option. However, some therapists have been accepting reduction of drinking as a treatment goal, often in conjunction with a cognitive-behavioural approach.

Pharmacotherapy is sometimes added to psychotherapy, the latter often based on 12-step treatment. Other forms of psychotherapy have been used as well, including family-based and psychodynamic approaches.

Common medications include tiapride, acamprosate, and disulfiram, with disulfiram being the most widely used in the postacute treatment phase (Neto, Lambaz, Aguiar, \& Chick, 2008) and in aftercare (Neto, Lambaz, \& Tavares, 2007). Disulfiram is used over a long period of time; one expert stated that the usual duration was two years, with supervision.

\section{ROMANIA}

Romania does not have a national set of guidelines, but the status quo of ADT in this country became clear through research and a survey of experts. Abstinence is considered the ultimate treatment goal in most treatment facilities. In government-sponsored hospitals, reduction of drinking is only accepted if abstinence cannot be achieved. However, there may be exceptions in private practices. Psychotherapy is strongly influenced by Alcoholics Anonymous and Minnesota-type treatments, as these are integrated in some hospitals. Some pharmacotherapy is used when deemed necessary; naltrexone is used, albeit rarely, as is it usually not covered.

\section{SLOVAKIA}

Slovakia does not have national guidelines for ADT. Based on the practice in clinics, abstinence seems to be the main treatment goal; however, abstinence is seen as a tool to reach the ultimate goal of regaining functionality within daily life (employment, marriage, etc.). With this in mind, if abstinence cannot be achieved, reduction of drinking is accepted as well. Psychotherapy, mainly CBT, and pharmacotherapy are utilized in ADT. Acamprosate is the most commonly used drug in pharmacotherapy.

\section{SLOVENIA}

There are national guidelines, with abstinence as the major goal. Most therapy (and all inpatient therapy) is based on the Hudolin model (Rus-Makovec \& Eebasek-Travnik, 2008), which is abstinence oriented as well. However, this therapy strives for more complete rehabilitation and reintegration into family and social 
life, with abstinence being the main tool to achieve this ultimate goal. Reduction of consumption can be seen as an intermediate step. Also, in outpatient care for people with low severity of alcohol dependence, controlled consumption can be an option. In pharmacotherapy, naltrexone is used both to support abstinence and to help with controlled drinking.

\section{SPAIN}

Spain has a set of professional guidelines that regulates the way patients with $\mathrm{AD}$ are managed (Guardia Serecigni, Arriero, Pastor, Menéndez, \& Guillamón, 2008); GPs also use guidelines developed for a European project (Anderson, Gual, \& Colom, 2005). The guidelines specify abstinence as the standard goal. However, reduced drinking is generally deemed acceptable as a treatment outcome for less severe dependence, as an alternative when abstinence fails, as an intermediate goal to achieving abstinence, or as an option that may be requested by the patient.

Psychotherapeutic measures that are commonly used include motivational interviewing, cognitive behavioral therapy and group therapy. Pharmacological treatment includes disulfiram (only under family supervision), naltrexone, topiramate and acamprosate, and is generally for a period of six to 12 months. Antidepressants are also frequently used to aid in psychotherapy. Benzodiazepanes are used, but restricted to the detox phase (Rehm, Rehm, Shield, Gmel, \& Gual, 2013).

\section{SWEDEN}

Sweden has national guidelines (http://www.socialstyrelsen.se/ publikationer2007/2007-102-1) for treatment of AD. The guidelines focus primarily on helping the patient reach a state where he can function again in society. This can be achieved in various ways, which means that controlled/reduced drinking is an acceptable treatment option next to abstinence (except in the case of pregnant users, where abstinence is the only goal, as a precautionary measure).

Patients with $\mathrm{AD}$ are managed by psychotherapy as well as pharmacotherapy. Psychotherapeutic measures include cognitive behavioral therapy, various 12-step programs, motivational interviewing, community reinforcement approaches, and brief interventions. There are also specific methods aimed at changing the drinking habits of the patient, as well as addressing any psychological or social problems that often go hand in hand with AD (p. 57 of the guidelines). Naltrexone, topiramate, and acamprosate are used in therapy for patients with the goals of both abstinence and reduction.

\section{SWITZERLAND}

Switzerland may be unique in its approach to ADT. While it has no official guidelines, surveys have concluded that $67 \%-93 \%$ of alcohol treatment providers agreed that reduction of alcohol consumption/controlled drinking was a viable treatment option (Klingemann et al., 2005; Meyer, 2009).

Otherwise, ADT generally mimics Germany (Klingemann et al., 2005). Pharmacotherapy and psychotherapy are both accepted and are often combined in treatment. This means integrated treatment models are the norm, a common one being a combination of CBT and acamprosate. The preferred style of psychotherapy is psychosocial, including psychoeducational and family therapeutic approaches. As part of this therapeutic style, efforts are made to integrate the patient's family and inner circle of friends into the therapeutic process. In pharmacotherapy, acamprosate is generally the administered drug; in the French-speaking regions, naltrexone is used as well.

\section{UNITED KINGDOM}

There are various regional guidelines concerning ADT throughout the UK. An official set of guidelines has been published by the Department of Health for England (http://www.lho.org.uk/ Download/Public/10776/1/Models\%20of\%20care\%20for\%20alcoh ol\%20misusers.pdf), based on the evidence of Raistrick et al. (2006), while national Scottish guidelines (Intercollegiate Guidelines Network, 2003) are also available.

Additionally, there are guidelines by the National Institute for Health and Clinical Excellence (NICE) (NICE, 2011). These are taken as the gold standard for evidence and have a quasi-legal status-a practitioner might have to explain why NICE guidance was not followed. However, NICE is formally still only guidance and not binding. Finally, there are guidelines by the British Association for Psychopharmacology, mainly limited to the pharmacological management of AD (Lingford-Hughes, Welch, \& Nutt, 2004). These guidelines were updated in 2012, and now include a larger section on pharmacological management of controlled drinking (Lingford Hughes et al., 2012).

The English and Scottish, as well as the NICE, guidelines agree that abstinence does not always have to be the ultimate goal of ADT. Although, generally, reduction is viewed as acceptable only when less severe $\mathrm{AD}$ is present, these guidelines allow for reduced consumption as a treatment option, and even the ultimate goal, for people with low to moderate $\mathrm{AD}$.

In the English guidelines (Raistrick, Heather \& Godfrey, 2006), pharmacotherapy and psychotherapy are usually administered in a combined treatment plan. Psychosocial treatments include cognitive-behavioral therapy, motivational enhancement therapy, 12-step facilitation therapy, coping and social skills training, community reinforcement approach, social behavior and network therapy, behavioral self-control training, and cognitive-behavioral marital therapy. Different types of medication are used (Raistrick et al., 2006): medications for treating patients with withdrawal symptoms during medically assisted alcohol withdrawal; medications to promote abstinence or prevent relapse; nutritional supplements, including vitamin supplements, as a harm reduction measure for heavy drinkers; and high-dose parenteral thiamin for the prevention and treatment of Wernicke's encephalopathy. The pharmacological treatment to promote abstinence and prevent relapse, which is usually combined with psychotherapy in treatment, includes disulfiram (under supervision) and acamprosate. Naltrexone has been recommended by NICE (NICE, 2011) and can be prescribed, although it does not currently have a license for use in alcohol dependence in the UK.

The Scottish guidelines (Intercollegiate Guidelines Network, 2003) recommend pharmacotherapy only in cases of severe dependence. Psychotherapeutic interventions also vary with the goal of treatment. When the goal is reduction, regular meetings with a trained psychiatrist are in order, to monitor and review progress. When the goal is abstinence, the patient's family and circle of close friends are often part of the treatment, as well as support groups such as AA, if this is wanted and deemed necessary. Acamprosate and/or disulfiram are used as medication to assist the psychotherapeutic treatment. 